\title{
Dietary starch promotes hepatic lipogenesis in barramundi (Lates calcarifer)
}

\author{
N. M. Wade ${ }^{1 *}$, L. H. Trenkner ${ }^{1,2}$, I. Viegas ${ }^{3,4}$, L. C. Tavares ${ }^{3}$, M. Palma ${ }^{1}$, S. Skiba-Cassy ${ }^{5}$, K. Dias ${ }^{5}$, C. Vachot ${ }^{5}$,
} B. C. Araújo ${ }^{1,6}$, N. Bourne ${ }^{1}$, D. Blyth ${ }^{7}$, S. Irvin' ${ }^{7}$ and B. D. Glencross ${ }^{1} \dagger$

${ }^{1}$ Commonwealth Scientific Industrial Research Organisation (CSIRO) Agriculture and Food, Queensland Biosciences Precinct, St Lucia, QLD 4067, Australia

${ }^{2}$ School of Agricultural and Food Sciences, The University of Queensland, St Lucia, QLD 4067, Australia

${ }^{3}$ Center for Neuroscience and Cell Biology (CNC), University of Coimbra, Coimbra 3004-517, Portugal

${ }^{4}$ Department of Life Sciences, Centre for Functional Ecology (CFE), University of Coimbra, Coimbra 3000-456, Portugal

${ }^{5}$ Institut National de la Recherche Agronomique (INRA), UMR1419 Nutrition, Metabolism, Aquaculture (NUMEA), E2S-UPPA, F-64310 Saint-Pée-sur-Nivelle, France

${ }^{6}$ Departamento de Fisiologia da Universidade de São Paulo, Instituto de Biociências, São Paulo, SP 05508-090, Brazil

${ }^{7}$ Commonwealth Scientific Industrial Research Organisation (CSIRO) Agriculture and Food, Bribie Island Research Centre, Bribie Island, QLD 4507, Australia

(Submitted 5 July 2019 - Final revision received 10 March 2020 - Accepted 10 March 2020 - First published online 19 March 2020)

\section{Abstract}

Barramundi (Lates calcarifer) are a highly valued aquaculture species, and, as obligate carnivores, they have a demonstrated preference for dietary protein over lipid or starch to fuel energetic growth demands. In order to investigate how carnivorous fish regulate nutritional cues, we examined the metabolic effects of feeding two isoenergetic diets that contained different proportions of digestible protein or starch energy. Fish fed a high proportion of dietary starch energy had a higher proportion of liver SFA, but showed no change in plasma glucose levels, and few changes in the expression of genes regulating key hepatic metabolic pathways. Decreased activation of the mammalian target of rapamycin growth signalling cascade was consistent with decreased growth performance values. The fractional synthetic rate (lipogenesis), measured by TAG ${ }^{2} \mathrm{H}$-enrichment using ${ }^{2} \mathrm{H}$ NMR, was significantly higher in barramundi fed with the starch diet compared with the protein diet $(0 \cdot 6$ (SE $0 \cdot 1) v$. 0.4 (SE 0.1) \% per d, respectively). Hepatic TAG-bound glycerol synthetic rates were much higher than other closely related fish such as sea bass, but were not significantly different (starch, $2 \cdot 8$ (SE 0.3 ) $v$. protein, 3.4 (SE 0.3 ) \% per d), highlighting the role of glycerol as a metabolic intermediary and high TAG-FA cycling in barramundi. Overall, dietary starch significantly increased hepatic TAG through increased lipogenesis. Compared with other fish, barramundi possess a unique mechanism to metabolise dietary carbohydrates and this knowledge may define ways to improve performance of advanced formulated feeds.

Key words: Liver: Fish: Nutrigenomics: ${ }^{2} \mathrm{H}$ : Lipogenic flux: NMR

Dietary energy is derived from three broad macronutrient classes: protein, lipid and carbohydrates (CHO) (such as starch). Metabolism of these macronutrient classes is known to occur with different levels of efficiency in terrestrial animals ${ }^{(1,2)}$ and has been examined in several fish species ${ }^{(3,4-8)}$. In past studies, varying the dietary macronutrient composition while maintaining the dietary digestible energy content resulted in significant changes in growth performance, feed utilisation and body composition $^{(5,6,9)}$. These studies across three different fish species showed that increasing dietary $\mathrm{CHO}$ composition reduced feed intake, growth and the efficiency of dietary energy utilisation, with a preference for protein-derived energy. This clearly indicated that dietary macronutrients were not utilised equally, despite the prevailing theory that only total dietary energy was important, but did not reveal how these effects might be occurring. Many studies have sought to understand the metabolic utilisation of glucose and other $\mathrm{CHO}$ in carnivorous fish ${ }^{(10,11)}$. Despite possessing shared metabolic pathways,

Abbreviations: acyl, ATP citrate lyase; Akt, serine/threonine specific protein kinase B; BW, body water; CHO, carbohydrate; cpt1a, carnitine palmitoyl transferase 1a; FA, fatty acid; fasn, fatty acid synthase; fbp1, fructose-1,6-bisphosphatase; FOXO1, forkhead homebox protein O1; FSR, fractional synthetic rate; g6pca, glucose-6-phosphatase; g6pd, glucose-6-phosphate dehydrogenase; gck, glucokinase; mTOR, mammalian target of rapamycin; pck1, phosphoenolpyruvate carboxykinase, cytosolic form; pck2, phosphoenolpyruvate carboxykinase, mitochondrial form; pk, pyruvate kinase; S6, ribosomal S6 kinase; S6K1, ribosomal protein S6 kinase beta-1; scd, stearoyl CoA desaturase; srebf1, sterol responsive element binding protein.

* Corresponding author: N. M. Wade, email nick.wade@csiro.au

$\dagger$ Present address: Institute of Aquaculture, University of Stirling, Stirling FK9 4LA, UK. 
fundamental differences in the hepatic and extra-hepatic regulation of dietary starch metabolism are beginning to be discovered in fish ${ }^{(12-15)}$.

Barramundi (Lates calcarifer) are an obligate carnivorous fish species at trophic level $3 \cdot 8^{(16)}$ and are the basis of a significant aquaculture industry in Southeast Asia and Australia ${ }^{(17)}$. A series of factorial bioenergetic nutritional models have been developed to provide estimations of feed demand and idealised feed compositions to support growth performance ${ }^{(18-21)}$. Although the aim in finfish aquaculture is to reduce dependence on protein (for costs and sustainability), there has been a resulting shift in dietary energy proportion towards formulations with higher levels of lipids and $\mathrm{CHO}$, with a range of implications for farmed fish $^{(13)}$. As expected for a carnivorous fish, growth performance and feed conversion in barramundi were more efficient when a high proportion of dietary energy was supplied as protein, followed by lipid energy ${ }^{(9)}$. However, a high proportion of dietary starch was also shown to restrict protein utilisation, suggesting a limited capacity for barramundi to utilise starch-derived energy over protein or lipid energy ${ }^{(22)}$. The types of physiological adaptations or underlying molecular mechanisms responsible for such differential macronutrient utilisation and subsequent growth performance are yet to be defined.

Molecular tools such as quantitative gene expression analysis have been successfully applied to understanding the effects of dietary nutrients on intermediary metabolism ${ }^{(23-26)}$. This includes key genes regulating glycolysis or gluconeogenesis (glucokinase $(g c k)$, pyruvate kinase $(p k)$, glucose-6-phosphatase ( $g б p c a)$ and fructose-1,6-bisphosphatase $(f b p 1)$ ), lipogenesis or lipid oxidation (ATP citrate lyase $(a c y l)$, stearoyl CoA desaturase $(s c d)$, fatty acid synthase (fasn), carnitine palmitoyl transferase 1a (cpt1a), glucose-6-phosphate dehydrogenase $(g \sigma p d)$ and sterol responsive element binding protein (srebf1)). In addition, the activation of signalling cascades (serine/threonine specific protein kinase B (Akt), mammalian target of rapamycin (mTOR), ribosomal S6 kinase (S6), ribosomal protein S6 kinase beta-1 (S6K1), forkhead homebox protein $\mathrm{O} 1$ (FoxO1) and FoxO1-3) has been defined as primary regulators of growth and metabolism in fish ${ }^{(25,27)}$. When sampled at peak times after feeding, these studies provide a snapshot of the molecular regulation underlying dietary metabolic changes ${ }^{(24)}$. As a complementary technique, the use of stable isotopes is further able to define metabolite flux and re-routing of major macronutrient metabolic pathways within tissues of fish fed different diets. Deuterated water $\left({ }^{2} \mathrm{H}_{2} \mathrm{O}\right)$ has been particularly effective for assessing contributions of gluconeogenesis to circulating glucose $^{(28)}$, direct or indirect pathways of hepatic glycogen synthesis ${ }^{(29,30)}$ or lipogenesis of hepatic $\mathrm{TAG}^{(31)}$ in European sea bass (Dicentrarchus labrax).

This study sought to evaluate the underlying mechanisms that regulate nutrient utilisation that potentially drive fish performance. Two experiments were used to investigate gene expression, signalling pathways and metabolic labelling changes that define metabolic nutrient preference and metabolic flux re-routing. The first used liver samples from barramundi fed either a high-protein or high-starch diet in a 12 -week growth performance study ${ }^{(9)}$. The second used liver samples from a complementary metabolic labelling experiment that fed fish the same two diets in the presence of ${ }^{2} \mathrm{H}_{2} \mathrm{O}$ to track the fate of dietary starch using ${ }^{2} \mathrm{H} \mathrm{NMR}^{(12)}$. These experiments defined several potential mechanisms that underlie the utilisation of dietary starch in barramundi. It also highlighted the diversity of mechanisms that regulate growth, metabolism and nutrient utilisation in fish as dietary protein is replaced by $\mathrm{CHO}$.

\section{Methods}

All experiments were performed in accordance with the Australian code of practice for the care and use of animals for scientific purposes and were approved by the CSIRO Animal Ethics Committee (approval numbers: A8-2010 and A8-2016).

\section{Fish Expt 1 - macronutrient source}

Samples from the protein and starch treatments from a previous experiment were used in this study ${ }^{(9)}$, where fish were fed diets formulated to the same digestible energy specifications but were biased to increase the relative contributions from protein or starch (Table 1). Twenty juvenile barramundi (81.2 (SE 1.48) g) were allocated to each of the six 300-litre tanks, maintained at $27 \cdot 8(\mathrm{se} 0.45)^{\circ} \mathrm{C}$, dissolved $\mathrm{O}_{2} 5.6(\mathrm{se} 0 \cdot 18) \mathrm{mg} / \mathrm{l}$, at flow rates of approximately 3 litres/min and under a $12 \mathrm{~h}$ light- $12 \mathrm{~h}$ dark photoperiod. Three replicate tanks were hand fed one of the two experimental diets for a period of 12 weeks. Diets were fed twice daily (09.00-09.30 and 16.30-17.00 hours) to slight excess based on the loss of observed feeding behaviour. All feed fed and all uneaten feed were accounted for and correction

Table 1. Formulation, proximate composition and digestible protein and energy parameters of the diets*

\begin{tabular}{lcc}
\hline & Protein diet & Starch diet \\
\hline Formulation & & \\
Fishmeal† & 640 & 560 \\
Gluten $\ddagger$ & 100 & 100 \\
Casein§ & 100 & 50 \\
Fish oil & 40 & 0 \\
Pregelled starch $\ddagger$ & 0 & 240 \\
Yttrium oxide & 2 & 2 \\
Vitamins and minerals\| & 5 & 5 \\
Cellulose§ & 113 & 43 \\
Composition & & \\
DM & 930 & 890 \\
Crude protein & 633 & 502 \\
Digestible protein & 575 & 448 \\
Total lipid & 117 & 66 \\
Ash & 90 & 115 \\
Total carbohydrates & 161 & 317 \\
Total starch & 16 & 325 \\
Gross energy (kJ/g DM) & $21 \cdot 3$ & $20 \cdot 8$ \\
Digestible energy (kJ/g DM) & $15 \cdot 9$ & $15 \cdot 2$ \\
Protein energy (\%) & 78 & 66 \\
Lipid energy (\%) & 19 & 11 \\
Starch energy (\%) & 0 & 20 \\
\hline Al & &
\end{tabular}

${ }^{*}$ All values are $\mathrm{g} / \mathrm{kg}$ DM basis unless otherwise shown.

† Peruvian anchoveta fishmeal and fish oil: Skretting Australia.

$\ddagger$ Wheat gluten and pre-gelatinised wheat starch: Manildra.

$\S$ Cellulose and vitamin-free casein: Sigma.

॥ Vitamin and mineral premix includes (g/kg of premix): vitamin $A, 0.75 \mathrm{~g}$; vitamin $D_{3}$, $6.3 \mathrm{mg}$; vitamin $\mathrm{E}, 16.7 \mathrm{~g}$; vitamin $\mathrm{K}, 3,1.7 \mathrm{~g}$; vitamin $\mathrm{B}_{1}, 2.5 \mathrm{~g}$; vitamin $\mathrm{B}_{2}, 4.2 \mathrm{~g}$; vitamin $B_{3}, 25 \mathrm{~g}$; vitamin $B_{5}, 8.3$; vitamin $B_{6}, 2.0$ g; vitamin $B_{9}, 0.8$; vitamin $B_{12}, 0.005 \mathrm{~g}$; biotin, $0.17 \mathrm{~g}$; vitamin $\mathrm{C}, 75 \mathrm{~g}$; choline, $166.7 \mathrm{~g}$; inositol, $58.3 \mathrm{~g}$; ethoxyquin, $20.8 \mathrm{~g}$; $\mathrm{Cu}$, $2.5 \mathrm{~g}$; ferrous $\mathrm{Fe}, 10.0 \mathrm{~g} ; \mathrm{Mg}, 16.6 \mathrm{~g} ; \mathrm{Mn}, 15.0 \mathrm{~g} ; \mathrm{Zn}, 25.0 \mathrm{~g}$. 
factors applied to obtain an accurate estimate of feed intake. At the end of the 12-week trial, four random fish from each of the three tank replicates for each treatment were sedated in anaesthetic Aqui-S ${ }^{\circledR}(0.02 \mathrm{ml} / \mathrm{l}) 2 \mathrm{~h}$ after their final meal, the time by which key gene regulatory pathways of intermediary metabolism in barramundi liver tend to peak ${ }^{(24)}$. Blood was collected by caudal vein puncture using a syringe pre-treated with a solution containing 0.2M EDTA, then centrifuged at $3000 \boldsymbol{g}$ for $5 \mathrm{~min}$ and the plasma transferred to a new tube and kept frozen at $80^{\circ} \mathrm{C}$ until analysis. Fish were euthanised by overdose in anaesthetic Aqui-S ${ }^{\circledR}(0.2 \mathrm{ml} / \mathrm{l})$ before liver samples were collected, snap frozen on dry ice and then stored at $-80^{\circ} \mathrm{C}$ prior to further RNA and protein analyses.

\section{Fish Expt 2 - metabolic labelling with ${ }^{2} \mathrm{H}_{2} \mathrm{O}$}

The greatest differences in growth performance were observed in fish fed a high proportion of dietary energy in the form of protein or starch; therefore, these two diets were further investigated through a metabolic tracer experiment, meaning that fish were fed their respective diets in the presence of deuterated (heavy) water $\left({ }^{2} \mathrm{H}_{2} \mathrm{O}\right)$. Initially, two treatment groups of thirty fish each (initial 51.3 (se 0.5) g) were housed in two independent 200 litre recirculated seawater systems maintained at 29.7 (SE 0.7) or 29.8 (SE 0.8$)^{\circ} \mathrm{C}$, respectively, and dissolved $\mathrm{O}_{2}$ of 6.4 (SE 1.0 ) or 6.8 (sE $0 \cdot 8) \mathrm{mg} / \mathrm{l}$, respectively. Each group was assigned to one of the two diets protein or starch (Table 1) and fed once daily (09.00 hours) to apparent satiety for $21 \mathrm{~d}$. The fish were sequentially transferred into a separate 200 litre tank enriched with about $3.5 \%{ }^{2} \mathrm{H}_{2} \mathrm{O}$ and fed to apparent satiety once per $\mathrm{d}$ for $5 \mathrm{~d}$ and sampled on day $6,24 \mathrm{~h}$ after their last meal. This ${ }^{2} \mathrm{H}_{2} \mathrm{O}$ tank was maintained with an independent closed filtering system but had similar characteristics to each of the holding tanks used during the feeding period in terms of size, volume of water (200 litres), opacity, filtering material and water parameters (28.0 (sE $0 \cdot 6)^{\circ} \mathrm{C}$ and dissolved $\mathrm{O}_{2}$ of 6.6 (sE 1.6) $\mathrm{mg} / \mathrm{l}$ ). Seawater was enriched by the addition of $99.9 \%{ }^{2} \mathrm{H}_{2} \mathrm{O}$ (Sigma catalogue no. 151882) as described previously ${ }^{(28)}$. Fish were sedated using $0.02 \mathrm{ml} / 1$ of anaesthetic Aqui- $\mathrm{S}^{\circledast}$, then measured, weighed and sampled for blood from the caudal vein with heparinised syringes. Approximately $100 \mu \mathrm{l}$ aliquot was centrifuged (3000 g, $10 \mathrm{~min}$ ), and plasma was stored for quantification of body water (BW) ${ }^{2} \mathrm{H}$-enrichments. Fish were then euthanised by an overdose in anaesthetic Aqui-S ${ }^{\circledR}(0 \cdot 2 \mathrm{ml} / \mathrm{l})$ before livers were excised, weighed and stored at $-80^{\circ} \mathrm{C}$ until further analysis.

\section{Metabolite assays}

Plasma glucose levels ( $n$ 12) were measured using an AccuCheckPerforma glucose meter (Roche). Plasma TAG levels (n 12) were determined using a colorimetric commercial kit adapted to microplates (Biomerieux). Plasma free amino acid levels ( $n$ 12) were determined using a fluorometric detection method ${ }^{(32)}$ and using Amino Acid Standard H (Pierce no. 20088) as a reference.

\section{Lipid quantification}

The determination of the fatty acid (FA) profile of diets and liver utilised an adapted protocol described by Coutteau \&
Sorgeloos ${ }^{(33)}$. Lipids were esterified by an acid-catalysed methylation and to each sample was added $0.3 \mathrm{mg}$ of an internal standard (21:0 Supelco). The FA methyl esters were separated by GC using an Agilent Technologies 6890N GC system (Agilent Technologies) fitted with a DB-23 capillary column. The carrier gas used was $\mathrm{H}_{2}$ at a flow rate of $40 \mathrm{ml} / \mathrm{min}$. The GC was programmed with the following temperature, $50-175^{\circ} \mathrm{C}$ at $25^{\circ} \mathrm{C}$ min then $175-230^{\circ} \mathrm{C}$ at $2 \cdot 5^{\circ} \mathrm{C}$ min. FA methyl esters were detected by a flame ionization detector with the injector and detector temperatures being set at 250 and $320^{\circ} \mathrm{C}$, respectively. The FA methyl esters were detected by comparing peak retention times to known standards (37 Comp. FAME mix, Supelco).

\section{Quantitative real-time $R T-P C R$}

Total RNA was extracted using Trizol reagent (Invitrogen), according to the manufacturer's instructions, and precipitated by adding 0.5 volumes of isopropyl alcohol and 0.5 volumes of RNA precipitation solution for purity improvement ${ }^{(34)}$. Total RNA was DNase digested with the Turbo DNA-free kit (Applied Biosystems). RNA quantity was assessed on a NanoDrop spectrophotometer (NanoDrop Technologies), and RNA quality was assessed using a Bioanalyser (Agilent Technologies) and RNA nanochips (Agilent no. 5067-1511). All RNA samples were diluted to $200 \mathrm{ng} / \mu \mathrm{l}$. Reverse transcription was performed on $1 \mu \mathrm{g}$ of total RNA using Superscript III (Invitrogen) with $25 \mu \mathrm{M}$ oligo $(d T)_{20}$, $25 \mu \mathrm{M}$ random hexamers and $400 \mathrm{pg}$ of luciferase RNA (Promega L4561) as an exogenous control gene.

Real-time PCR amplification using primers specific to each gene of interest (online Supplementary Table S1) was performed as previously described ${ }^{(24)}$. Real-time PCR amplification reactions were carried out using $1 \mathrm{X}$ SYBR Green PCR Master Mix (Applied Biosystems); $0 \cdot 2 \mu \mathrm{M}$ of each primer and the equivalent of $7.5 \mathrm{ng}$ of reverse-transcribed RNA. Amplification cycle conditions were $2 \mathrm{~min}$ at $50^{\circ} \mathrm{C}, 10 \mathrm{~min}$ at $95^{\circ} \mathrm{C}$ followed by forty cycles of $15 \mathrm{~s}$ at $95^{\circ} \mathrm{C}$ and $40 \mathrm{~s}$ at $60^{\circ} \mathrm{C}$. Verification that there was no genomic DNA contamination was carried out by PCR amplification of a pool of DNAse-treated RNA samples using gene-specific primers. Normalisation was performed using the $\Delta C q$ method (where $C q$ is the quantification cycle), and expression levels of each gene relative to one another were determined by normalising the cycle threshold values for each gene to the endogenous control gene $E f 1 \alpha$ and the exogenous Luciferase control, then to the average cycle threshold of each gene relative to the control diet. The variation in amplification of eef1a 1 or luciferase across all samples was 0.63 and 0.10 cycles, respectively (data not presented).

\section{Protein extraction and Western blotting}

Frozen liver samples (about $100 \mathrm{mg}$ ) were extracted as previously described $^{(24)}$, and the resulting supernatants ( $n 9$ for each treatment) were stored at $-80^{\circ} \mathrm{C}$ until required. Protein concentrations were determined using the Bio-Rad Protein assay kit. Quantities of $20 \mu \mathrm{g}$ protein per sample were separated by SDS-PAGE and analysed for the presence of specific proteins by Western blotting and using the appropriate antibodies. Primary antibodies for the analysis of signalling pathways were obtained from Cell Signaling Technologies (Akt-p no. 9272; Akt 
no. 9271; mTOR-p no. 2972; mTOR no. 2971; S6-p no. 4856; S6 no. 2217S; S6K1-p no. 9205; S6K1 no. 9202; FoxO1-p no. 9461; FoxO1-3-p no. 9464 and Tubulin no. 2775) or Epitomics (Labome FKHR (Fox-O1) no. 1874-1) and used at a dilution of 1:1000 as described previously ${ }^{(35)}$. After incubation with a goat anti-rabbit IRDye infrared secondary antibody (LI-COR Inc. Biotechnology), bands were visualised and quantified by Infrared fluorescence using the Odyssey Imaging System (LI-COR Inc. Biotechnology).

\section{Metabolite preparation}

To obtain a sufficient amount of analytes for generating ${ }^{2} \mathrm{H}$ NMR spectra with a high signal:noise ratio, the livers of five fish were pooled into six replicate groups (pooled analyses: $n 6$ per diet). Lipids were extracted from homogenised livers according to Matyash et al. ${ }^{(36)}$ using a mixture of methyl tert-butyl ether (Sigma) and methanol (Sigma). Briefly, homogenised livers were added to a mixture of methyl tert-butyl ether:methanol, and after phase separation, the upper lipid phase was carefully separated. The lipid extract was further fractionated into TAG and NEFA using solid-phase extraction (SPE) with prepacked $2 \mathrm{~g}$ cartridges (Discovery ${ }^{\circledR}$ DSC-NH $\mathrm{N}_{2}$ 52641-U, Supelco) according to Ruiz et al. ${ }^{(37)}$. Hepatic TAG and NEFA extracts were analysed separately by ${ }^{2} \mathrm{H}$ NMR. Hepatic TAG quantifications were performed in a fully-automated analyzer Miura 200 (I.S.E. S.r.l.) using a dedicated TAG reagent kit (ref. A-R0100000901; $n$ 5).

\section{${ }^{1} \mathrm{H}$ and ${ }^{2} \mathrm{H} N \mathrm{NM}$ analysis of lipids}

Tank water and fish BW ${ }^{2} \mathrm{H}$-enrichments were analysed in duplicate from $10 \mu \mathrm{l}$ samples of water and plasma by ${ }^{2} \mathrm{H}$ NMR as described previously ${ }^{(38)}$. Tank and plasma water content was assumed to be $96.5 \%$ (35\% salinity) and $92.0 \%{ }^{(39)}$ of total sample, respectively. NMR spectra of TAG and NEFA samples were obtained at $25^{\circ} \mathrm{C}$ with a Bruker Avance III HD system with an UltraShield Plus magnet $\left(11.7 \mathrm{~T},{ }^{2} \mathrm{H}\right.$ operating frequency $500 \mathrm{MHz}$ ) equipped with a $5-\mathrm{mm}{ }^{2} \mathrm{H}$-selective probe with $19 \mathrm{~F}$ lock and ${ }^{1} \mathrm{H}$-decoupling coil. Lipids were reconstituted in chloroform containing a pyrazine standard as previously described ${ }^{(40)}$ generating well-resolved spectra (online Supplementary Fig. S1). As control for the TAG extraction, a FA:glycerol ratio was calculated from the area of all FA $\alpha$ protons (online Supplementary Fig. S1(a)); A) times 2, divided by TAG-glycerol sn-1,3 protons (online Supplementary Fig. S1(a)); L). If successful, a TAG-only extraction theoretical FA:glycerol ratio should be approximately $3^{(41)}$. As control for the NEFA extraction, all spectra were confirmed for absent glycerol sn-1,3 proton signals. The FA profile (in percentage) for SFA and unsaturated FA, both PUFA and MUFA were estimated by ${ }^{2} \mathrm{H}$ NMR according to Viegas et al. ${ }^{(31)}$.

Positional ${ }^{2} \mathrm{H}$-enrichments were quantified from the ${ }^{1} \mathrm{H}$ and ${ }^{2} \mathrm{H}$ NMR spectra by measuring the ${ }^{1} \mathrm{H}$ and ${ }^{2} \mathrm{H}$ intensities of selected signals relative to the ${ }^{1} \mathrm{H}$ and ${ }^{2} \mathrm{H}$ intensities of a pyrazine standard, after correction for linoleic acid contribution according to Duarte et al. ${ }^{(41)}$. Briefly, this involved, (1) the determination of the ${ }^{2} \mathrm{H}$-enrichment in the FA terminal methyl group for both TAG-bound FA and NEFA derived from lipogenesis (online Supplementary Fig. S1; A); (2) the determination of the
${ }^{2} \mathrm{H}$-enrichment in the sn-1,3 glycerol site for newly synthesised or cycled TAG-bound glycerol (online Supplementary Fig. S1; L); (3) the determination of the ${ }^{2} \mathrm{H}$-enrichment in the MUFA's allylic protons for desaturation of SFA (online Supplementary Fig. S1; F). Moreover, while the terminal methyl group is enriched with ${ }^{2} \mathrm{H}$ during the first round of FA synthesis (thus indicative of DNL), the $\alpha$ protons (online Supplementary Fig. S1; H) incorporate ${ }^{2} \mathrm{H}$ in the last round of elongation. Therefore, if elongation occurs on pre-existing (unlabeled) FA, the $\alpha$ - and methyl protons will be differentially labelled and will inform of the fractional contribution of elongation to lipid synthesis.

Fractional synthetic rates (FSR; in \% per d) from (1) lipogenesis; (2) newly synthesised/cycled glycerol; (3) desaturation and (4) elongation rates (\% per d) were estimated by dividing the respective positional ${ }^{2} \mathrm{H}$-enrichments by that of $\mathrm{BW}$. ${ }^{2} \mathrm{H}$-enrichments were calculated after systematic subtraction of the values with $0.015 \%$, taken as the mean background ${ }^{2} \mathrm{H}$-enrichment ${ }^{(41)}$. If the values were below zero, these were considered as $0 \cdot 0$ for FSR calculation purposes.

\section{Statistical analyses}

For comparison of the relationships between blood chemistry, gene expression and signalling pathways, each value was normalised to the average of the entire group and then $\log _{2^{-}}$ transformed. Prior to statistical comparison, measured values were assessed for normality using a Kolmogorov-Smirnov test. Where comparison between individual measurements was required, statistical significance was assessed by $t$ test analysis of means allowing $5 \%$ error. Statistical analyses were performed using a combination of StatPlus:Mac 2009 (AnalystSoft Inc.), Statistica (StatSoft) or R-software packages (R-Core Team). For ${ }^{1} \mathrm{H}$ and ${ }^{2} \mathrm{H}$ NMR analysis of lipids, Student's two-tailed unpaired $t$ test was used to compare means between dietary treatments. Analyses were performed in GraphPad Prism software (GraphPad Software). Differences were considered statistically significant at $P<0.05$.

\section{Results}

\section{Plasma metabolites}

Levels of plasma metabolites were largely unaffected by the proportion of dietary energy supplied as different macronutrients at the sample time assessed. No significant differences were observed between the diets for plasma glucose, TAG levels or free amino acid (Table 2).

\section{Liver lipids}

When the FA content of the liver of animals fed the starch diet was compared with the protein diet, liver TAG levels were significantly elevated (Table 2). After separation of liver FA by GC, there was a significant elevation in the proportion of SFA (38.8-41.3\%) and MUFA (29.5-33.9\%), along with a significant decrease in PUFA (24.9-18.8\%), in particular $n$-3 PUFA (online Supplementary Table S2). Differences were predominantly caused by changes in $16: 0$ and $18: 1 n-9$ cis FA. Decreased proportions were recorded for EPA $(7 \cdot 8-4 \cdot 2 \%)$, DPA $(2 \cdot 7-1 \cdot 8 \%)$ 
Table 2. Plasma and liver metabolites

(Mean values with their standard errors)

\begin{tabular}{|c|c|c|c|c|}
\hline & \multicolumn{2}{|c|}{ Protein } & \multicolumn{2}{|c|}{ Starch } \\
\hline & Mean & SEM & Mean & SEM \\
\hline \multicolumn{5}{|l|}{ Plasma $(n$ 12) $\dagger$} \\
\hline Glucose (mmol/l) & $5 \cdot 4$ & 0.6 & $8 \cdot 0$ & $1 \cdot 2$ \\
\hline $\mathrm{TAG}(\mathrm{g} / \mathrm{l})$ & 1.0 & 0.5 & $1 \cdot 4$ & 0.8 \\
\hline Free amino acids $(\mu \mathrm{mol} / \mathrm{l})$ & 553 & 38 & 452 & 37 \\
\hline \multicolumn{5}{|l|}{ Liver $(n 6) \ddagger$} \\
\hline TAG (mg/g tissue) & $5 \cdot 7$ & $1 \cdot 3$ & $11 \cdot 9^{\star}$ & 1.6 \\
\hline
\end{tabular}

Significant difference between diets $\left(t\right.$ test; $\left.{ }^{*} P<0.05\right)$.

† From fish Expt 1 - macronutrient source, $2 \mathrm{~h}$ post-feeding

† From fish Expt 2 - metabolic labelling with ${ }^{2} \mathrm{H}_{2} \mathrm{O}$.

and DHA $(6 \cdot 3-4 \cdot 5 \%)$. The $n-3: n-6$ ratio found in the liver was significantly lower in starch fed fish compared with protein fed fish (2.9-1·6; online Supplementary Table S2). There was also a shift in the proportion of FA in the liver compared with the levels of FA in the diets, dependent upon the dietary treatment. Compared with the levels in the diet, liver SFA significantly increased by $10.8 \%$ in animals fed the starch diet, along with a $7.9 \%$ increase in MUFA. This caused the greatest relative reduction in liver PUFA in the starch diet fed animals, with $24.7 \%$ less PUFA recorded in the liver than in the diet.

The liver lipid analysis as obtained by ${ }^{1} \mathrm{H}$ NMR for the ${ }^{2} \mathrm{H}_{2} \mathrm{O}$ experiment corroborated this profile and statistical changes for the protein and starch diets (online Supplementary Table S3). TAG ${ }^{1} \mathrm{H}$ NMR analysis revealed a consistent FA:glycerol ratio of approximately 3 for protein-fed fish (3.1 (SE 0.1)) and starch-fed fish (3.0 (sE 0.1)), while NEFA ${ }^{1} \mathrm{H}$ NMR spectra showed no presence of glycerol peaks (online Supplementary Fig. S1(a) (inlet at $4 \cdot 14$ parts per million)). Finally, after the metabolic tracer experiment, hepatic TAG levels were significantly elevated in fish fed with the starch diet (Table 2).

\section{Gene expression}

Gene expression changes at $2 \mathrm{~h}$ after feeding were generally small, but the expression of several genes was significantly affected by varying the dietary macronutrient source. Compared with the protein diet, barramundi fed the starch diet showed significantly decreased expression of $p k$ and $f b p 1$ but increased expression of $p c k 2$. None of the genes regulating FA synthesis or breakdown was affected by diet.

\section{Signalling pathways}

There were very few significant changes in the phosphorylation of various signalling molecules in response to different dietary macronutrients. At $2 \mathrm{~h}$ after feeding, there was a significant down-regulation in the level of phosphorylated mTOR in fish fed the starch diet (Fig. 2). A similar trend was observed in the average phosphorylation status of $56,56 \mathrm{~K} 1$ and FoxO1-3 in starch-fed fish, although this decrease was not significant (Fig. 2). Phosphorylation of FoxO1 tended to increase in response to a starch diet, but again was not considered significant.
Table 3. Fractional synthetic rate (FSR) for hepatic NEFA and TAG-bound fatty acids (FA) and glycerol (expressed as percentage of newly synthesised FA from lipogenesis per d; FSR in \% per d) and modification (elongation and desaturation) rates (expressed as $\%$ of $F A$ ) in barramundi (Lates calcarifer) fed with protein or starch diet, after a $6 \mathrm{~d}$ residence in a tank with approximately $3.5 \%{ }^{2} \mathrm{H}$-enriched water (Mean values with their standard errors; $n 6$ unless indicated)

\begin{tabular}{llllll}
\hline & \multicolumn{2}{c}{ Protein } & & \multicolumn{2}{c}{ Starch } \\
\cline { 2 - 3 } FSR $(\%$ per $d)$ & Mean & SEM & & Mean & SEM \\
\hline NEFA & 0.78 & 0.29 & & 0.85 & 0.10 \\
$\quad$ Elongation rate & $0.77 \dagger$ & 0.35 & & $0.44 \ddagger$ & 0.23 \\
Desaturation rate & ND & & & ND & \\
TAG-bound FA & 0.35 & 0.09 & & $0.62^{\star}$ & 0.07 \\
TAG-bound glycerol & 3.40 & 0.31 & & 2.82 & 0.29 \\
Elongation rate & 0.44 & 0.08 & & $0.12^{\star *}$ & 0.04 \\
Desaturation rate & 0.30 & 0.12 & & 0.50 & 0.06 \\
\hline
\end{tabular}

ND, not detected.

Significant differences between diets $\left(t\right.$ test; ${ }^{*} P<0.05,{ }^{* \star} P<0.01$ ).

† $n 5$ (1 ND).

$\ddagger n 4$ (2 ND).

\section{Lipogenic flux from ${ }^{2} \mathrm{H}_{2} \mathrm{O}$}

Equilibration of BW and tank water was confirmed, with no apparent differences being observed on either diet (protein-fed fish: BW 3.25 (SE 0.09) $v$. tank water 3.46 (SE 0.19); starch-fed fish: BW 3.74 (SE 0.12) $v$. tank water 3.79 (SE 0.04); ${ }^{2} \mathrm{H}$-enrichment in \%). Separate estimations for lipogenesis revealed differential fluxes for hepatic lipids. The FSR for TAG-bound FA was significantly increased in the starch-fed fish (starch 0.6 (se 0.1) \% perd; protein 0.4 (se 0.1) \% perd; $P=0.035$ ), while the FSR for NEFA was unaffected by diet (starch 0.9 (sE 0.1) \% per d; protein 0.8 (se 0.3) \% per d; $P>0.05$ ) (Fig. 3; Table 3). The FSR for newly synthesised/cycled TAG-bound glycerol was similarly unaffected by diet (starch-fed fish $2 \cdot 8$ (se 0.3) \% per d; protein-fed fish 3.4 (se 0.3) \% per d; $P>0.05$ ), even though the FSR of TAG-bound glycerol was found to be 5-10-fold higher than the FSR for TAG-bound FA (Table 3). Estimations for modifications of FA revealed different dynamics (Table 3). For TAG-bound FA, the rate of elongation was significantly lower in starch-fed fish, while the rate of desaturation showed no statistical difference, even if slightly elevated in starch-fed fish compared with protein-fed fish. For NEFA, elongation rates were calculated in nine out of the twelve samples. These revealed no statistical difference between diets. Peaks for calculating desaturation rates on the other hand were not detected in all samples (online Supplementary Fig. S1(b) inlet). In agreement with the increased FSR for TAG-bound FA, there was a significant increase in total hepatic TAG in starch-fed fish (protein 5.7 (sE 1.3) mg/g tissue; starch 11.9 (sE 1.6) mg/g tissue).

\section{Discussion}

Presently, there is no understanding of the molecular mechanisms that regulate intermediary metabolism in barramundi, a highly valued species of global importance, in response to feeding different dietary energy sources. This study combined gene 
expression and signalling cascades with a metabolic labelling approach to define the hepatic mechanisms by which barramundi assimilate and store excess dietary $\mathrm{CHO}$ energy. These changes underlie the significantly reduced growth performance (protein $3.72 \mathrm{~g} / \mathrm{d}$, starch $3.32 \mathrm{~g} / \mathrm{d}$ ) ${ }^{(9)}$, increased lipid deposition efficiency (protein $77.3 \%$, starch 182.8\%) ${ }^{(9)}$ and reduced protein energy utilisation coefficient (protein $\theta k_{P E}=0.557$, starch $\left.\theta k_{P E}=0.412\right)^{(22)}$ observed in barramundi attributed to the replacement of dietary protein with plant-based raw materials that contain high levels of digestible $\mathrm{CHO}$.

\section{Plasma metabolites and hepatic gene expression}

Most carnivorous fish display an elevation of blood glucose levels and prolonged periods of hyperglycaemia after consuming a
CHO-rich diet, often associated with increased glycolytic and lipogenic enzyme activity and gene expression ${ }^{(10,11,42)}$. Similar to most carnivorous fish, certain forms of starch are highly digested by barramundi ${ }^{(43,44)}$, including $>85 \%$ digestibility of the pre-gelatinised starch in this study ${ }^{(9)}$. However, $2 \mathrm{~h}$ after consuming a high-starch meal, barramundi showed no significant elevation of plasma glucose, TAG or free amino acid compared with protein-fed fish (Table 2). The expression of genes regulating key metabolic pathways was also largely unaffected, with the exception of $p k, f b p 1$ and $p c k 2$ (Fig. 1). The lack of increased acyl or fas expression do not suggest that lipogenesis was affected, although strong evidence demonstrating this role was defined in the metabolic labelling experiment, as is further discussed below. This is despite evidence that many barramundi
(A)
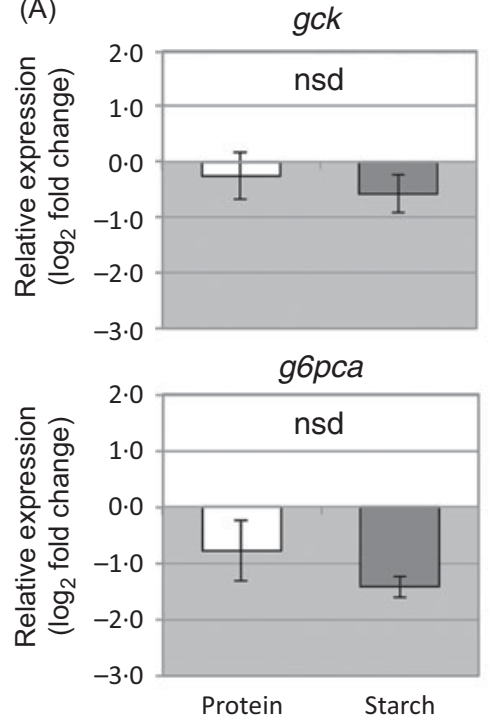

(B)
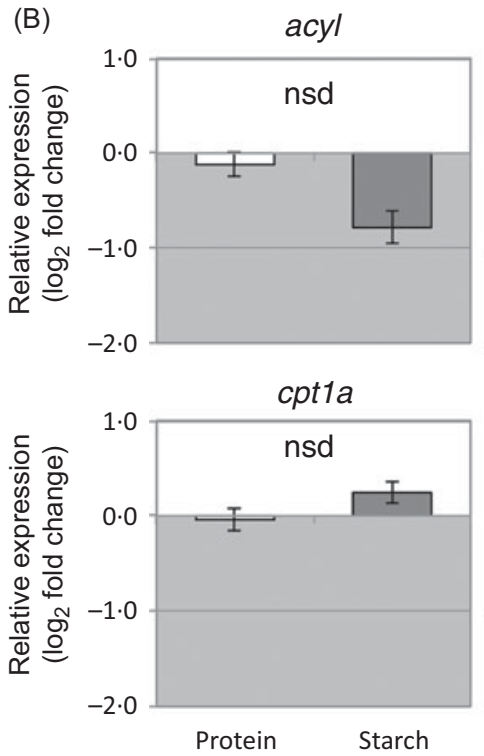

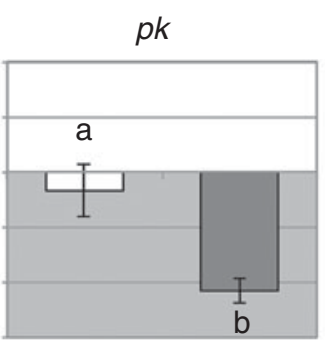

fbp1
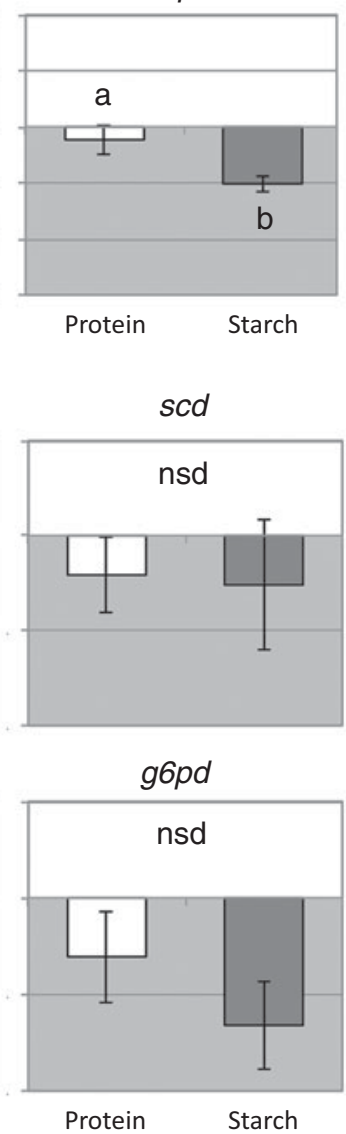

Fig. 1. Change in liver expression of genes regulating glucose metabolism (A) or fatty acid metabolism (B) in fish fed a diet that differed in protein or starch macronutrient composition. Expression values are shown as $\log _{2}$-fold change of each gene relative to the expression in the protein diet. ${ }^{a, b}$ Unlike letters indicate significant $(P<0.05)$ differences between the different diets; nsd denotes no significant difference. 
(A) Protein
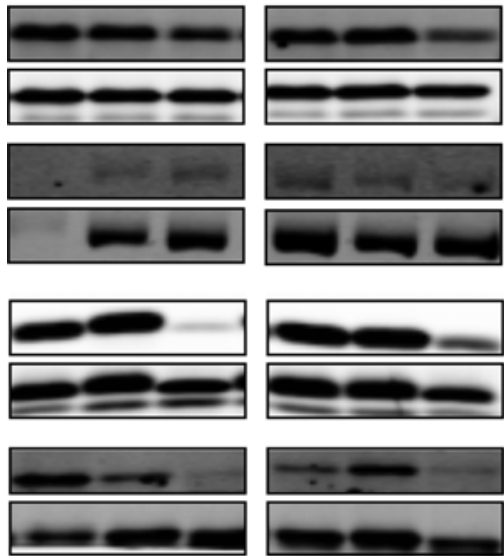

$\mathrm{P}-\mathrm{S} 6$
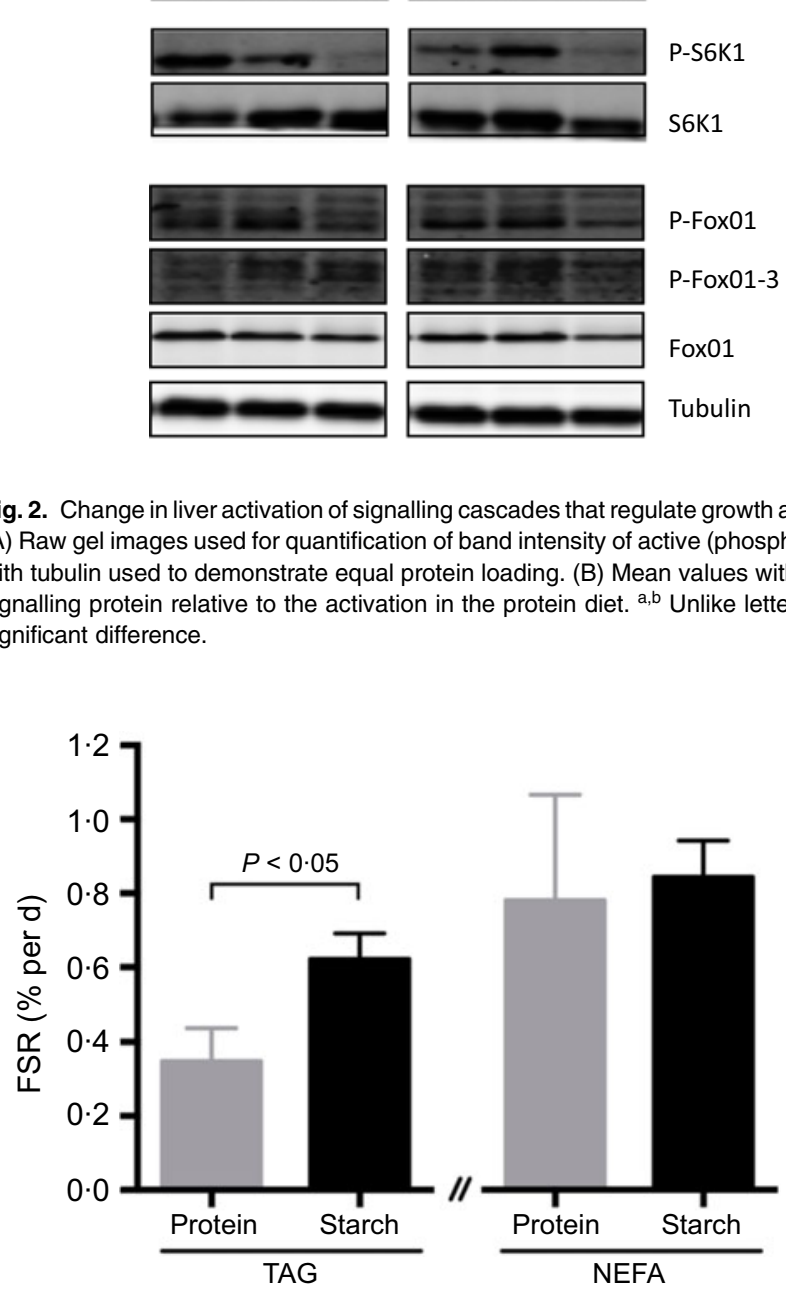

Fig. 3. Fractional synthetic rate (FSR) for TAG-bound fatty acid (FA) and NEFA, expressed as percentage of newly synthesised FA from lipogenesis per $d$ in hepatic lipids of barramundi (Lates calcarifer) fed with a protein or starch diet, after a 6 -d residence in a tank with approximately $3.5 \%{ }^{2} \mathrm{H}$-enriched water. Mean values with their standard errors are presented $(n 6)$. A significant differ-

ence between diets is indicated $(t$ test; $P<0.05)$.

genes displayed significant postprandial regulation, including $g k, g 6 p c a, a c y l$ and $f a s^{(24)}$, which implies the expression of these genes is regulated in a coordinated way after feeding.

In rainbow trout Oncorbynchus mykiss, elevated dietary starch levels of more than $20 \%$ have been shown to significantly elevate both plasma glucose and hepatic $g k$ gene expression and enzyme activity ${ }^{(45-47)}$. Barramundi are most closely related to significant difference.
(B)
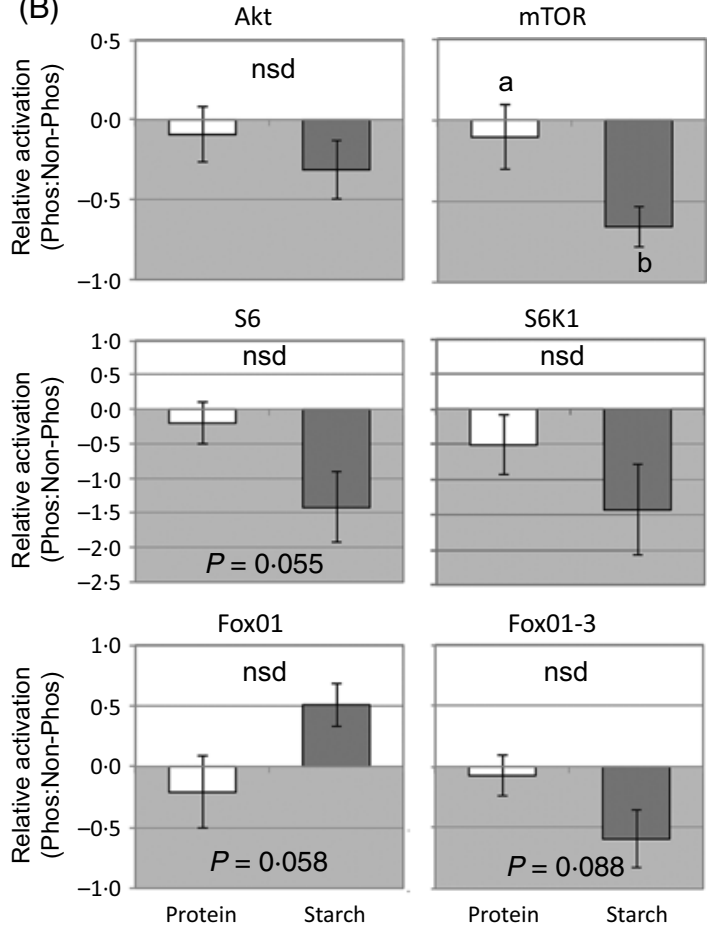

Fox01-3

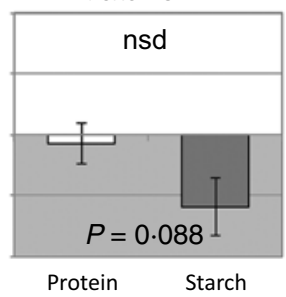

Fig. 2. Change in liver activation of signalling cascades that regulate growth and metabolism in fish fed a diet that differed in protein or starch macronutrient composition. signalling protein relative to the activation in the protein diet. ${ }^{a, b}$ Unlike letters indicate significant $(P<0.05)$ differences between the different diets; nsd denotes no 
expression $2 \mathrm{~h}$ after feeding as part of their response to dietary $\mathrm{CHO}$ (Fig. 2). However, although endogenous gluconeogenesis was also significantly repressed in sea bass fed $30 \%$ dietary starch $^{(29)}$, half the circulating glucose in starch-fed fish was still derived from gluconeogenic pathways. Gluconeogenesis remains a major contributor of hepatic glucose-6-phosphate synthesis in carnivorous fish ${ }^{(58)}$, yet the precise contribution of gluconeogenesis in barramundi glucose utilisation remains to be determined. Combined, molecular data suggest that there is at least one component of the gluconeogenic pathway strongly decreased (phosphoenolpyruvate carboxykinase, cytosolic form (pck1), gбpca or $f b p 1$ ), and/or at least one component of the glycolytic pathway strongly increased $(g k, p f k l$ or $p k$ ). These responses form part of a variety of species-specific mechanisms involved in fish metabolism of dietary $\mathrm{CHO}$, although that utilisation remains universally poor in most carnivorous fish $^{(51)}$.

\section{Growth signalling cascades}

Previous work has shown that the starch-fed fish used in this study had approximately $11 \%$ reduced growth than the protein-fed fish ${ }^{(9)}$ and that this was potentially caused by a reduction in the utilisation of total energy $\left(k_{E}\right.$ protein $=0 \cdot 715$, starch $=0.481$ ) mostly due to reduced protein energy utilisation $\left(\theta k_{P E} \text { protein }=0.557, \text { starch }=0.412\right)^{(22)}$. Therefore, analysis of the activation of the mTOR signalling cascade in barramundi provides a potential mechanism to explain the poor growth performance observed in fish-fed high-starch diets. Changes in phosphorylation status were subtle, and only significant in mTOR and S6, but consistent with the peak of activation of these signalling proteins at the time of sampling ${ }^{(24)}$ and their relative position within the signalling cascade ${ }^{(25,27)}$. The role of mTOR as a regulator of growth and whole-body metabolism ${ }^{(59)}$ is consistent with evidence in barramundi that suggests that as starch levels increase, there is a direct negative effect on growth and energy utilisation, particularly that of protein ${ }^{(22)}$. However, past work in trout has shown that dietary fishmeal replacement with plant ingredients (maize and wheat gluten) did not induce differences in the Akt-mTOR signalling pathway ${ }^{(27)}$. In addition, trout Akt-mTOR activation has been shown to be a key regulator of hepatic lipogenesis through stimulation of srebf1, fas and $g k$ expression ${ }^{(25)}$, which was not evident in barramundi. Meanwhile, $2 \mathrm{~h}$ after a meal of a high-lipid diet, Senegalese sole (Solea senegalensis) displayed prolonged hyperglycaemia and down-regulated the Akt-mTOR signalling pathway, while a high-CHO diet had no effect ${ }^{(60)}$. The results of this study combined with past work favours the notion that species-specific mechanisms are central to glucose homoeostasis in carnivorous fish, but may provide a potential basis for the ineffective utilisation of this macronutrient as a direct energy source for growth in barramundi.

\section{Hepatic lipids and lipogenic flux}

Tracer methods provide direct measurements of lipogenic fluxes ${ }^{(61-66)}$, but have still not been widely applied in fish. ${ }^{2} \mathrm{H}_{2} \mathrm{O}$ in particular rapidly equilibrates with fish $\mathrm{BW}^{(28)}$ and gets incorporated into newly synthesised or exchanged metabolites as described for glucose and glycogen synthesis in sea bass ${ }^{(28-30)}$, lipogenesis of hepatic ${ }^{(31)}$ and extrahepatic ${ }^{(12)}$ TAG, hepatic alanine metabolism in gilthead sea bream ${ }^{(67)}$, and muscle protein synthesis in catfish (Ictalurus punctatus) ${ }^{(68)}$. In barramundi, hepatic lipogenesis was significantly increased (Fig. 3), which provides direct support for the accumulation of hepatic TAG (Table 2) and FA (online Supplementary Table S2) and increased lipid retention and deposition from high-starch diets ${ }^{(9,22)}$. Dietary lipid levels were reduced in the starch diet, leading to significantly reduced gross lipid intake (protein 31.0; starch $19.6 \mathrm{~g}$ per fish) in starch-fed fish despite a slight increase in feed intake ${ }^{(9)}$. This reduced intake may partially explain the approximately $25 \%$ improved lipid retention but cannot account for the $182 \%$ lipid deposition that is demonstrated here to be a direct result of increased lipogenesis.

Metabolic flux for NEFA revealed no lipogenic increase, no elongation rate alterations, and no evidence for any desaturation. In a similar feeding and tracer administration setting, sea bass revealed that TAG levels were significantly augmented in the liver in response to high-starch diets ${ }^{(29)}$, but this feature could not be attributed to an increase in hepatic TAG-bound FA from lipogenesis. Meanwhile, muscle TAG levels remained unaltered, but TAG-bound FA from lipogenesis significantly increased in starch-fed fish, indicative of TAG-FA recycling in response to diet $^{(12)}$. In barramundi, no enrichment of muscle TAG could be detected, but in visceral fat, TAG-bound FA and glycerol synthesis/cycling was elevated by starch diets ${ }^{(12)}$, although the rate of lipogenesis was approximately 6-fold higher rates in liver tissue. Changes in endogenous lipids and TAG consisted of increased SFA and MUFA at the expense of PUFA, with SFA accumulation mainly driven by an increase in palmitate $(16: 0)$, the end product of lipogenesis. Combined, the strong enhancement of visceral fat lipogenesis and high TAG-glycerol cycling in starch-fed fish ${ }^{(12)}$ further supports the accumulation of large amounts of visceral fat and modifications to whole-body composition observed in barramundi as a result of consuming high-starch diets ${ }^{(22)}$.

Observations from other carnivorous species further substantiate that the unaltered expression of lipid synthesis-related gene expression or enzymes $2 \mathrm{~h}$ after a meal should not be interpreted as lack of lipogenic potential from dietary starch per $s e^{(42)}$. In gilthead sea bream, dietary starch affected lipid absorption and transport, probably due to a delay in lipid absorption ${ }^{(69)}$, which would delay any potential response from FAS for several hours. As outlined above, studies in rainbow trout demonstrated that amino acids, and not $\mathrm{CHO}$, are potent stimulators of lipogenesis ${ }^{(70)}$. While mRNA abundance and enzymatic rates involved in the metabolism of dietary $\mathrm{CHO}$ provide valuable insights, the ${ }^{2} \mathrm{H}_{2} \mathrm{O}$ experiment captured metabolic changes of free-swimming fish fed over $6 \mathrm{~d}$. Changes in endogenous TAG and glycerol synthesis rates provide a holistic lipogenic flux profile that is independent of short-term post-prandial, circadian or stress-induced enzymatic or gene expression fluctuations.

\section{Conclusion}

This study demonstrates that barramundi utilise a unique series of specific hepatic regulatory mechanisms to assimilate and store 
excess dietary $\mathrm{CHO}$ energy in the form of lipids, to the detriment of protein utilisation and growth. This study also highlights the potential advantages of using metabolic tracers to track dietary nutrient assimilation over several days of feeding, as this method overcomes many of the limitations of molecular-based studies that select a single time point (often 2,6 or $24 \mathrm{~h}$ post-feeding) to draw conclusions. Although metabolic pathways are shared among carnivorous fish, results from hepatic enzyme assays, gene expression and signalling cascades, as well as lipogenic and metabolic flux analysis, support the notion that there is significant diversity in the underlying regulation of dietary nutrient assimilation in different fish species. This study provides a deeper understanding of the metabolic utilisation of feed ingredients in barramundi and therefore the ability to formulate advanced species-specific feeds.

\section{Acknowledgements}

The authors would like to thank Simon Tabrett, Natalie Habilay, Dean Musson, Nick Polymeris and Mike Anderson for assistance with trial maintenance, and Ben Maynard for assistance with trial sampling. The authors would like to thank João Rito and John Jones for assisting in the NMR analysis.

This work was supported by a grant from the Australian Centre for International Agricultural Research (ACIAR) project FIS-2006-141 and co-funded by CSIRO Agriculture and Food. In addition, this work was supported by Fundação para a Ciência e Tecnologia (FCT; Portugal) through national funds with the co-funding by the FEDER, within the PT2020 Partnership Agreement, and COMPETE 2020 (IV SFRH/BPD/ 90032/2012; MP Centro2020 - ReNATURE; Centro-01-0145FEDER-000007). The authors also thank Artur Rombenso for considered revision of this manuscript.

Authors' responsibilities were as follows: B. D. G., I. V. and N. M. W. designed experiments, D. B., S. I. and L. H. T. performed experiments, B. A., N. B., K. D., M. P., L. C. T., L. H. T., C. V., I. V. and N. M. W. performed laboratory analyses and analysed the data. N. M. W., B. D. G., I. V. and S. S. wrote the manuscript. All authors read and approved the final version of the manuscript.

The authors declare that there are no conflicts of interest.

\section{Supplementary material}

For supplementary materials referred to in this article, please visit https://doi.org/10.1017/S0007114520001051

\section{References}

1. Azevedo PA, van Milgen J, Leeson S, et al. (2005) Comparing efficiency of metabolizable energy utilization by rainbow trout (Oncorbynchus mykiss) and Atlantic salmon (Salmo salar) using factorial and multivariate approaches. J Anim Sci $\mathbf{8 3}$, 842-851.

2. Hua K, Birkett S, De Lange CFM, et al. (2010) Adaptation of a non-ruminant nutrient-based growth model to rainbow trout (Oncorbynchus mykiss Walbaum). J Agric Sci 148, 17-29.
3. Bureau DP \& Hua K (2008) Models of nutrient utilization by fish and potential applications for fish culture operations. In Mathematical Modelling in Animal Nutrition, pp. 442-461 [J France and E Kebreab, editors]. Wallingford: CAB International.

4. Dumas A, France J \& Bureau D (2010) Modelling growth and body composition in fish nutrition: where have we been and where are we going? Aquacult Res 41, 161-181.

5. Saravanan S, Schrama JW, Figueiredo-Silva AC, et al. (2012) Constraints on energy intake in fish: the link between diet composition, energy metabolism, and energy intake in rainbow trout. PLOS ONE 7, e34743.

6. Schrama JW, Saravanan S, Geurden I, et al. (2012) Dietary nutrient composition affects digestible energy utilisation for growth: a study on Nile tilapia (Oreochromis niloticus) and a literature comparison across fish species. Br J Nutr 108, 277-289.

7. Pérez-Jiménez A, Carmen Hidalgo M, Morales AE, et al. (2009) Growth performance, feed utilization and body composition of Dentex dentex fed on different macronutrient combinations. Aquacult Res 41, 111-119.

8. Pérez-Jiménez A, Hidalgo MC, Morales AE, et al. (2009) Use of different combinations of macronutrients in diets for dentex (Dentex dentex): effects on intermediary metabolism. Comp Biochem Physiol Part A Mol Integr Physiol 152, 314-321.

9. Glencross B, Blyth D, Irvin S, et al. (2014) An analysis of the effects of different dietary macronutrient energy sources on the growth and energy partitioning by juvenile barramundi, Lates calcarifer, reveal a preference for protein-derived energy. Aquacult Nutr 20, 583-594.

10. Polakof S, Panserat S, Soengas JL, et al. (2012) Glucose metabolism in fish: a review. J Comp Physiol B 182, 1015-1045.

11. Moon $\mathrm{T}$ (2001) Glucose intolerance in teleost fish: fact or fiction? Comp Biochem Phys B 129, 243-249.

12. Viegas I, Trenkner LH, Rito J, et al. (2019) Impact of dietary starch on extrahepatic tissue lipid metabolism in farmed European (Dicentrarchus labrax) and Asian seabass (Lates calcarifer). Comp Biochem Phys A 231, 170-176.

13. Kamalam BS, Medale F \& Panserat S (2017) Utilisation of dietary carbohydrates in farmed fishes: new insights on influencing factors, biological limitations and future strategies. Aquaculture 467, 3-27.

14. Chen YJ, Zhang TY, Chen HY, et al. (2017) An evaluation of hepatic glucose metabolism at the transcription level for the omnivorous GIFT tilapia, Oreochromis niloticus during postprandial nutritional status transition from anabolism to catabolism. Aquaculture 473, 375-382.

15. Panserat S, Rideau N \& Polakof S (2014) Nutritional regulation of glucokinase: a cross-species story. Nutr Res Rev 27, 21-47.

16. Froese R \& Pauly D (editors) (2019) FishBase. World Wide Web electronic publication. www.fishbase.org (accessed December 2019).

17. Jerry DR (2013) Biology and Culture of Asian Seabass, Lates calcarifer. Boca Raton, FL: CRC Press, Taylor and Francis Group.

18. Bermudes M, Glencross B, Austen K, et al. (2010) The effects of temperature and size on the growth, energy budget and waste outputs of barramundi (Lates calcarifer). Aquaculture 306, 160-166.

19. Glencross B \& Bermudes M (2010) Effect of high water temperatures on the utilisation efficiencies of energy and protein by juvenile barramundi, Lates calcarifer. Fish Aquacult J 14, 1-11.

20. Glencross BD (2008) A factorial growth and feed utilization model for barramundi, Lates calcarifer based on Australian production conditions. Aquacult Nutr 14, 360-373.

21. Glencross BD \& Bermudes M (2012) Adapting bioenergetic factorial modelling to understand the implications of heat stress on 
barramundi (Lates calcarifer) growth, feed utilisation and optimal protein and energy requirements - potential strategies for dealing with climate change? Aquacult Nutr 18, 411-422.

22. Glencross BD, Blyth D, Bourne N, et al. (2017) An analysis of partial efficiencies of energy utilisation of different macronutrients by barramundi (Lates calcarifer) shows that starch restricts protein utilisation in carnivorous fish. Br J Nutr 117, 500-510.

23. Skiba-Cassy S, Panserat S, Larquier M, et al. (2013) Apparent low ability of liver and muscle to adapt to variation of dietary carbohydrate:protein ratio in rainbow trout (Oncorbynchus mykiss). Br J Nutr 109, 1359-1372.

24. Wade NM, Skiba-Cassy S, Dias K, et al. (2014) Postprandial molecular responses in the liver of the barramundi, Lates calcarifer. Fish Physiol Biochem 40, 427-443.

25. Dai W, Panserat S, Mennigen JA, et al. (2013) Post-prandial regulation of hepatic glucokinase and lipogenesis requires the activation of TORC1 signalling in rainbow trout (Oncorbynchus mykiss). J Exp Biol 216, 4483-4492.

26. Panserat S \& Kaushik SJ (2010) Regulation of gene expression by nutritional factors in fish. Aquacult Res 41, 751-762.

27. Lansard M, Panserat S, Seiliez I, et al. (2009) Hepatic protein kinase B (Akt) - target of rapamycin (TOR)-signalling pathways and intermediary metabolism in rainbow trout (Oncorbynchus mykiss) are not significantly affected by feeding plant-based diets. Br J Nutr 102, 1564-1573.

28. Viegas I, Mendes VM, Leston S, et al. (2011) Analysis of glucose metabolism in farmed European sea bass (Dicentrarchus labrax L.) using deuterated water. Comp Biochem Physiol A Mol Integr Physiol 160, 341-347.

29. Viegas I, Rito J, Jarak I, et al. (2015) Contribution of dietary starch to hepatic and systemic carbohydrate fluxes in European seabass (Dicentrarchus labrax L.). Br J Nutr 113, 1345-1354.

30. Viegas II, Rito JJ, Jarak II, et al. (2012) Hepatic glycogen synthesis in farmed European seabass (Dicentrarchus labrax L.) is dominated by indirect pathway fluxes. Comp Biochem Physiol A Mol Integr Physiol 163, 22-29.

31. Viegas I, Jarak I, Rito J, et al. (2016) Effects of dietary carbohydrate on hepatic de novo lipogenesis in European seabass (Dicentrarchus labrax L.). J Lipid Res 57, 1264-1272.

32. Fisher G, Arias I, Quesada I, et al. (2001) A fast and sensitive method for measuring picomole levels of total free amino acids in very small amounts of biological tissues. Amino Acids 20, 163-173.

33. Coutteau P \& Sorgeloos P (1995) Intercalibration Exercise on the Qualitative and Quantitative Analysis of Fatty Acids in Artemia and Marine Samples Used in Mariculture. Copenhagen: ICES.

34. Green MR \& Sambrook J (2012) Molecular Cloning: a Laboratory Manual. Cold Spring Harbor, NY: Cold Spring Harbor Laboratory Press.

35. Seiliez I, Gabillard JC, Skiba-Cassy S, et al. (2008) An in vivo and in vitro assessment of TOR signaling cascade in rainbow trout (Oncorbynchus mykiss). Am J Physiol Regul Integr Comp Physiol 295, R329-R335.

36. Matyash V, Liebisch G, Kurzchalia TV, et al. (2008) Lipid extraction by methyl-tert-butyl ether for high-throughput lipidomics. J Lipid Res 49, 1137-1146.

37. Ruiz J, Antequera T, Andres AI, et al. (2004) Improvement of a solid phase extraction method for analysis of lipid fractions in muscle foods. Anal Chim Acta 520, 201-205.

38. Jones JG, Merritt M \& Malloy C (2001) Quantifying tracer levels of $\left(\mathrm{H}_{2} \mathrm{O}\right)-\mathrm{H}-2$ enrichment from microliter amounts of plasma and urine by H-2 NMR. Magn Reson Med 45, 156-158.

39. Krebs HA (1950) Chemical composition of blood plasma and serum. Annu Rev Biochem 19, 409-430.
40. Viegas I, Araujo PM, Rocha AD, et al. (2017) Metabolic plasticity for subcutaneous fat accumulation in a long-distance migratory bird traced by ${ }^{2} \mathrm{H}_{2} \mathrm{O}$. J Exp Biol 220, 1072-1078.

41. Duarte JA, Carvalho F, Pearson M, et al. (2014) A high-fat diet suppresses de novo lipogenesis and desaturation but not elongation and triglyceride synthesis in mice. J Lipid Res $\mathbf{5 5}$, 2541-2553.

42. Enes P, Panserat S, Kaushik S, et al. (2008) Nutritional regulation of hepatic glucose metabolism in fish. Fish Physiol Biochem 35, 519-539.

43. Glencross B, Blyth D, Tabrett S, et al. (2012) An assessment of cereal grains and other starch sources in diets for barramundi (Lates calcarifer) - implications for nutritional and functional qualities of extruded feeds. Aquacult Nutr 18, 388-399.

44. Allan GL, Booth M, Stone DAJ, et al. (2003) Aquaculture diet development subprogram: ingredient evaluation. $N S W$ Fish Final Rep Ser 58, 150.

45. Panserat S, Médale F, Blin C, et al. (2000) Hepatic glucokinase is induced by dietary carbohydrates in rainbow trout, gilthead seabream, and common carp. Am J Physiol Regul Integr Comp Physiol 278, 1164-1170.

46. Panserat S, Plagnes-Juan E \& Kaushik S (2002) Gluconeogenic enzyme gene expression is decreased by dietary carbohydrates in common carp (Cyprinus carpio) and gilthead seabream (Sparus aurata). Biochim Biophys Acta 1579, 35-42.

47. Capilla E, Médale F, Navarro I, et al. (2003) Muscle insulin binding and plasma levels in relation to liver glucokinase activity, glucose metabolism and dietary carbohydrates in rainbow trout. Regul Pept 110, 123-132.

48. Enes P, Panserat S, Kaushik S, et al. (2011) Dietary carbohydrate utilization by European sea bass (Dicentrarchus labrax L.) and gilthead sea bream (Sparus aurata L.) juveniles. Rev Fish Sci 19, 201-215.

49. Meton I, Caseras A, Fernandez F, et al. (2004) Molecular cloning of hepatic glucose-6-phosphatase catalytic subunit from gilthead sea bream (Sparus aurata): response of its mRNA levels and glucokinase expression to refeeding and diet composition. Comp Biochem Physiol B Biochem Mol Biol 138, $145-153$.

50. Caseras A, Meton I, Fernandez F, et al. (2000) Glucokinase gene expression is nutritionally regulated in liver of gilthead sea bream (Sparus aurata). Biochim Biophys Acta 1493, $135-141$.

51. Skiba-Cassy S, Polakof S, Seiliez I, et al. (2012) Functional genomic analysis of the nutritional and hormonal regulation of fish glucose and lipid metabolism. In Functional Genomics in Aquaculture, pp. 129-146 [M Saroglia and ZJ Liu, editors]. Oxford: Wiley-Blackwell.

52. Caseras A, Meton I, Vives C, et al. (2002) Nutritional regulation of glucose-6-phosphatase gene expression in liver of the gilthead sea bream (Sparus aurata). Br J Nutr 88, 607-614.

53. Garcia-Rejon L, Sanchez-Muros MJ, Cerda J, et al. (1997) Fructose 1,6 bisphosphatase activity in liver and gonads of sea bass (Dicentrarchus labrax). Influence of diet composition and stage of the reproductive cycle. Fish Physiol Biochem 16, 93-105.

54. Bonamusa L, De Frutos PG, Fernandes F, et al. (1992) Nutritional effects on key glycolytic-gluconeogenic enzyme activities and metabolite levels in the liver of the teleost fish Sparus Aurata. Mol Mar Biol Biotech 1, 113-124.

55. Meton I, Mediavilla D, Caseras A, et al. (1999) Effect of diet composition and ration size on key enzyme activities of glycolysisgluconeogenesis, the pentose phosphate pathway and amino acid metabolism in liver of gilthead sea bream (Sparus aurata). Br J Nutr 82, 223-232. 
56. Enes P, Panserat S, Kaushik S, et al. (2006) Effect of normal and waxy maize starch on growth, food utilization and hepatic glucose metabolism in European sea bass (Dicentrarchus labrax) juveniles. Comp Biochem Physiol A 143, 89-96.

57. Kirchner S, Kaushik S \& Panserat S (2003) Low protein intake is associated with reduced hepatic gluconeogenic enzyme expression in rainbow trout (Oncorbynchus mykiss). J Nutr 133, 2561-2564.

58. Viegas I, Rito J, González JD, et al. (2013) Effects of fooddeprivation and refeeding on the regulation and sources of blood glucose appearance in European seabass (Dicentrarchus labrax L.). Comp Biochem Physiol A Mol Integr Physiol 166, 399-405.

59. Polak P \& Hall MN (2009) mTOR and the control of whole body metabolism. Curr Opin Cell Biol 21, 209-218.

60. Borges P, Valente LMP, Veron V, et al. (2014) High dietary lipid level is associated with persistent hyperglycaemia and downregulation of muscle Akt-mTOR pathway in senegalese sole (Solea senegalensis). PLOS ONE 9, e102196.

61. Ekmann KS, Dalsgaard J, Holm J, et al. (2013) Effects of dietary energy density and digestible protein: energy ratio on de novo lipid synthesis from dietary protein in gilthead sea bream (Sparus aurata) quantified with stable isotopes. Br J Nutr 110, 1771-1781.

62. Ekmann KS, Dalsgaard J, Holm J, et al. (2013) Glycogenesis and de novo lipid synthesis from dietary starch in juvenile gilthead sea bream (Sparus aurata) quantified with stable isotopes. $\mathrm{BrJ}$ Nutr 109, 2135-2146.

63. Felip O, Ibarz A, Fernandez-Borras J, et al. (2012) Tracing metabolic routes of dietary carbohydrate and protein in rainbow trout (Oncorbynchus mykiss) using stable isotopes $\left(\left[{ }^{13} \mathrm{C}\right]\right.$ starch and $\left[{ }^{15} \mathrm{~N}\right]$ protein): effects of gelatinisation of starches and sustained swimming. Br J Nutr 107, 834-844.

64. Hemre GI \& Kahrs F (1997) ${ }^{14} \mathrm{C}$-glucose injection in Atlantic cod, Gadus morbua, metabolic responses and excretion via the gill membrane. Aquacult Nutr 3, 3-8.

65. Hemre GI \& Storebakken T (2000) Tissue and organ distribution of ${ }^{14} \mathrm{C}$-activity in dextrin-adapted Atlantic salmon after oral administration of radiolabelled ${ }^{14} \mathrm{C}_{1}$-glucose. Aquacult Nutr 6, 229-234.

66. Magnoni L, Vaillancourt E \& Weber JM (2008) High resting triacylglycerol turnover of rainbow trout exceeds the energy requirements of endurance swimming. Am J Physiol Regul Integr Comp Physiol 295, R309-R315.

67. Gonzalez JD, Caballero A, Viegas I, et al. (2012) Effects of alanine aminotransferase inhibition on the intermediary metabolism in Sparus aurata through dietary amino-oxyacetate supplementation. Br J Nutr 107, 1747-1756.

68. Gasier HG, Previs SF, Pohlenz C, et al. (2009) A novel approach for assessing protein synthesis in channel catfish, Ictalurus punctatus. Comp Biochem Physiol B Biochem Mol Biol 154, $235-238$.

69. Castro C, Corraze G, Basto A, et al. (2016) Dietary lipid and carbohydrate interactions: implications on lipid and glucose absorption, transport in gilthead sea bream (Sparus aurata) juveniles. Lipids 51, 743-755.

70. Dai WW, Panserat S, Plagnes-Juan E, et al. (2015) Amino acids attenuate insulin action on gluconeogenesis and promote fatty acid biosynthesis via mTORC1 signaling pathway in trout hepatocytes. Cell Physiol Biochem 36, 1084-1100. 